\title{
The Pivotal Role of Lifestyle Medicine Physician in Managing Chronic Diseases
}

\author{
Prof. Iqbal Akhtar Khan ${ }^{1}$ \\ 1 MBBS DTM FACTM PhD, Independent Scholar, Lahore, Pakistan \\ *Corresponding Author: Prof. Iqbal Akhtar Khan, MBBS DTM FACTM PhD, Independent Scholar, Lahore, Pakistan. \\ Email: profiakhan@gmail.com;
}

Received: March 23, 2020; Accepted: May 21, 2020

\begin{abstract}
Background: Chronic diseases are presently the leading cause of morbidity and mortality and are responsible for most of health care expenditure, both in wealthiest countries and those with limited resources. Aims and Objectives: To ratify the competence of skill set Lifestyle Medicine Physician in identifying multiple factors tied to individual's health. Study Design: To define the attributes of a Lifestyle Medicine Physician. Material and Methods: The role of the Lifestyle Medicine Physician in introducing meaningful, measurable, attainable and sustainable lifestyle interventions which are acceptable, doable and enjoyable for the target group, has been described. In addition the important effect of Spirituality, in the context of the Palliative Care Guidelines of the World Health Assembly and on the increasing toll of Physician Burnout, has been highlighted. Results: Implementation of lifestyle recommendations, under the guidance of Lifestyle Medicine Physician, can significantly reduce premature disability and mortality. Conclusion: The skill set physicians who, with strong basic knowledge, would be able to identify the multiple factors tied to individual 's health, provide individualized advice and succefully change menance of chronic lifestyle-related diseases..
\end{abstract}

Keywords: Lifestyle Medicine, Five Star Doctor, Behavioral modification, Spirituality, Patient engagement, Physician burnout.

\section{INTRODUCTION}

By ignoring the root causes of disease and neglecting to prioritize lifestyle measures for prevention, the medical community is placing people at harm. We believe that lifestyle medicine should become the primary approach to the management of chronic conditions and, more importantly, their prevention"

—Dr. Balazs Bodai et al. [1]

Chronic diseases have surpassed infectious diseases as the leading cause of worldwide mortality. According to WHO's Situation and Trends, of the 56.9 million global deaths in 2016, 40.5 million (71\%), were due to chronic diseases. By 2030, this figure may reach 52 million [2].

Whereas it is known that more than $80 \%$ of chronic conditions could be avoided through the adoption of healthy lifestyle recommendations. [3], the ongoing acceptance and adoption of a healthy lifestyle remains greatest challenge even in the wealthiest countries.

The American Cardiologist James Rippe, Founder of The Rippe
Lifestyle Institute, coined the term "Lifestyle Medicine" defining it as "the discipline of studying how daily habits and practices impact both on the prevention and treatment of disease, often in conjunction with pharmaceutical or surgical therapy, to provide an important adjunct to overall health" [4].

The definition has changed with time. The American College of Lifestyle Medicine defines it as "the combined use of a whole food, plant-predominant diet, regular physical activity, restorative sleep, stress management, avoidance of risky substances and positive social connection in a prescribed synergistic manner as a primary therapeutic modality for the treatment and reversal of chronic disease" [5].

According to Australian researchers " it is not meant to be an alternative to conventional clinical practice, but rather a means to address the health challenges posed by changes to lifestyle in the past three to four decades ${ }^{[6]}$.

Whereas lifestyle medicine requires patients to be more active in their own care, it is the physician who will advise on the recommended lifestyle measures to facilitate living with a chronic condition.

The present study is aimed at defining the role of lifestyle 
medicine physician in managing chronic diseases, through lifestyle interventions.

\section{ATTRIBUTES OF A LIFESTYLE MEDICINE PHYSICIAN}

"Prescribing lifestyle interventions begins with possessing a clear health behavior- change skill set that includes comfort with tools such as motivational interviewing, positive psychology, and cognitive behavioral therapy". (W S Dysinger) ${ }^{[7]}$.

Although, WHO had the view that "Doctors of tomorrow may not be doctors of the day-after-tomorrow, as societies and health systems evolve and adaptation to current and anticipated needs continue", certain universally essential skills characterize what the WHO calls the "Five Star Doctor" CARE PROVIDER, DECISION MAKER, COMMUNICATOR, COMMUNITY $\angle E A D E R$ and MANAGER). The concept was first described by Dr Charles Boelen, of the WHO, in $1993^{[8]}$ and endorsed by the World Organization of National Colleges and the Academies and Academic Associations of General Practitioners/Family Physicians (WONCA).

While the five attributes, described above, may equally apply to any family physician, "Lifestyle Medicine Physician" comes close to fulfilling the concept of the "Five Star Doctor". Additionally, when equipped with the tools of motivational competency and a well-defined health-behavior change skill, he/she is able to introduce meaningful, measurable and attainable lifestyle interventions which are acceptable, doable and enjoyable for the target group. Conversely, any lapse in his/her competence will adversely affect the anticipated results. This is exemplified by the sub-optimal outcomes described in a study, conducted by Faculty of Medicine at the University of Oulu, in Finland, entitled "Physicians discuss the risks of smoking with their patients, but seldom offer practical cessation support", in which the smoking cessation program did not meet the desired success because the physicians were themselves inadequately acquainted with the clinical guidelines and proven strategies for such an endeavor ${ }^{[9]}$.

There is growing evidence among clinicians and health policy makers about the benefits of increased patient engagement, which is defined as "actions individuals must take to obtain the greatest benefit from the health care services available to them" [10]. The role of the clinician is a strong determinant of the level of patient engagement. The effectiveness of clinicians' efforts to counsel patients about behavior change are dependant upon the patient's level of engagement.

\section{MISCONCEPTIONS AND MYTHS}

Not infrequently the "Lifestyle Medicine Physician" may come across misconceptions and myths voiced by patients. It is necessary to discuss these with them, to win their confidence and possibly their cooperation to manage these health issues.

Research conducted at the State University of New York (SUNY) identified "misconceptions" as the major potential barrier preventing or delaying Obstructive Sleep Apnea evaluation and treatment ${ }^{[11]}$. This applies to other chronic diseases too.

\section{SYNERGISTIC ROLE OF DIET AND EXERCISE}

"Physicians know the importance of diet, but this is something they cannot prescribe. Instead, they send their patients to consult with nutritionists"

(Byung-IL Yeh and In Deok Kong)— [12]
Although Prof. Charles Denison, emphasised the importance of physical exercise and healthy food for the health of "pulmonary invalids", in his inspiring treatise "Exercise and Food for Pulmonary Invalids", the advice is valid for other chronic diseases too. Its roots can be traced to the Aphorisms of Hippocrates - "eating alone will not keep a man well; he must also take exercise, for food and exercise work together to produce health". Hippocratic physicians believed that food was medicine and vice versa. Unfortunately, overnutrition has become a global epidemic. In fact, the quality in terms of constituents is of more relevance than the quantity ${ }^{[13]}$.

In an American survey, Gardner et al found that only $38 \%$ of meals were home-made and many people had never cooked a meal from basic ingredients [14]. Moreover, there is a greater tendency to snack between meals. According to estimates in 2016 , the majority $(71 \%)$ of snackers in the UK snack once a day or more, with over one quarter (27\%) snacking twice a day, and $7 \%$ snacking three times a day or more.

Multipronged strategies, to combat adverse obesogenic environments with resultant reduction in mortality from coronary heart disease, have been successful in Finland and Mauritius. Between 1972 and 1992, dietary changes, in the form of reducing the consumption of high-fat milk from $70 \%$ to $14 \%$, resulted in a drop of mean total serum cholesterol level by $16 \%$, in the North Karelia province of Finland ${ }^{[15] .}$

In Mauritius, a five year nationwide intervention program for NCDs was associated with a reduction of mean serum cholesterol level from $5.5 \mathrm{mmol} / \mathrm{l}$ in 1987 to $4.7 \mathrm{mmol} / \mathrm{l}$ in 1992 . The improvement was attributed to a change from using a local cooking oil rich in palm oil to one with almost $100 \%$ soybean oil, with its lower saturated fat content ${ }^{[16]}$. The role of the Lifestyle Medicine Physician in the success of such programs is pivotal, for example in devising initiatives such as "Know the age of your lungs" - introduced in Torun and Bydgoszcz in Poland, offering spirometric examination and anti-nicotine interventions ${ }^{[17]}$.

The American Heart Association and the American Diabetes Association, using consensus panels to create practice guidelines, have recommended that "living a healthy lifestyle by getting plenty of exercise and eating a nutritious diet are the keys to minimize cardiovascular disease risk, before adding medication". Needless to say this advice is applicable to other chronic diseases too.

Interestingly, the word "diet", first appearing in English in the 13th century, meant "habitually taken food and drink". But it also means: "an eating plan", "a day's work", "lead one's life" and "a prescribed way of life" (from the Greek ठíaıта丿). The first mention of the phrase 'you are what you eat' is in the famous treatise "Physiology of Taste" by the French author Anthelme BrillatSavarin (1755-1826): "Tell me what you eat and I will tell you what your are." Literally in this quote "what you eat" means diet ("habitually taken food and drink.") but it could also mean how one is leading one's life or what is the prescribed way of one's life. The latter interpretation would be more meaningful.

Egger appropriately labels exercise and nutrition as the "penicillin" of lifestyle medicine; and psychology as the "syringe" through which they are delivered, in conjunction with relevant specialists ${ }^{[5]}$.

The slogan "Exercise is Medicine (EIM)" has its roots in antiquity. It is like medicine because it can be prescribed in a specific formulation, dosage, frequency and duration on an individualized basis. The concept is old but is gaining ground. 
Robert Sallis, President of the American College of Sports Medicine (ACSM) was right to assert "if we had a pill that conferred all the proven health benefits of exercise, physicians would widely prescribe it to their patients and our healthcare system would see to it that every patient had access to this wonder drug."

On November 5, 2007, the ACSM, with endorsement from the American Medical Association and the Office of the Surgeon General, launched a global initiative to educate healthcare providers about the benefits of exercise for a wide variety of conditions. Its roots can be traced to the teachings of Maha Rishi Susruta (floruit $1500 \mathrm{BCE}$ ), a strong advocate of the "Tridosa Doctrine" (explaining the relationship between health and disease) and the first "recorded" physician to prescribe exercise for his patients and to indicate that "it should be taken every day" but "only to half extent of his capacity" as otherwise "it may prove fatal". The ACSM recommends healthy adults perform 150 minutes of moderate dynamic exercise per week.

\section{SPIRITUALITY}

The palliative care guidelines of the World Health Assembly (WHA) state that all healthcare professionals have an ethical obligation to address all the suffering of patients - including psychosocial and spiritual.

Spirituality, an emerging and fascinating field, has been defined by Puchalski et al as "the way individuals seek and express meaning and purpose and the way they experience their connectedness to the moment, to self, to others, to nature, and to the significant or sacred" [18]. According to the 2013 International Consensus Conference on Improving the Spiritual Dimension of Whole Person Care, spirituality is defined as "a dynamic and intrinsic aspect of humanity through which persons seek ultimate meaning, purpose, transcendence, and experience relationship to self, family, others, community, society, nature, and the significant or sacred. Spirituality is expressed through beliefs, values, traditions, and practices" [19]. In this definition, spirituality is inseparable from humanity.

The compelling impact of spirituality on the occurrence and outcomes of numerous chronic diseases including COPD [20], has been well recognized. The toll of chronic disease and physician burnout is on the increase, and addressing spirituality is both relevant and timely. Burnout, a maladaptive work-related condition characterized by emotional exhaustion, depersonalization and a lack of personal accomplishment [21] affects $30 \%$ to $78 \%$ of physicians and residents ${ }^{[22,23]}$ and can lead to an increased prevalence of disruptive behavior in the workplace, and serious problems for the physician personally [24]. McCord et al found that $83 \%$ of patients in a family practice setting "wanted physicians to ask about [their] spiritual beliefs in at least some circumstances". Among those who wanted to discuss spirituality, $87 \%$ indicated "the most important reason for discussion was desire for physician-patient understanding" [25].

Baumann ${ }^{[26]}$ and Franzen ${ }^{[27]}$ conclude that patients with strong spirituality can use various coping and adaptive strategies such as problem-solving and positive reappraisal, and are more selfconfident and accepting of social support, with the added benefits for care-givers of improvement in their problem-solving and communication skills.

In a survey of family physicians in Missouri in 1999, the most frequently cited barriers to discussion of spiritual matters with patients were lack of time $(71 \%)$, lack of training $(59 \%)$ and uncertainty about how to manage spiritual issues raised by patients $(49 \%)^{[28]}$. It was through the enthusiasm of Prof.
Christina Puchalski, a pioneer and international leader in the movement to integrate spirituality into healthcare in both the clinical setting and in medical education, that the George Washington University started the Institute for Spirituality and Health (GWish) in May 2001.

\section{PHYSICIANS' HABITS AND OWN HEALTH}

"A modified clinical approach, based around the concept of lifestyle medicine, helps fill the gap by adding behavioural, motivational and environmental skills to conventional medical practices"

Garry J Egger.et al. [29]

A much-neglected issue in the practice of lifestyle medicine is that of physicians' own health and lifestyle choices. As the primary source of health education, they are role models (and they should be) for their patients. Naturally, their own health behaviors do have a strong impact on their competency to convince. The question raised by Howe et al "Patient-related diet and exercise counseling: do providers' own lifestyle habits matter?" is very valid [30]. The definitive answer is "YES". In a study conducted in Yale University, Puhl et al documented that physicians perceived to be overweight or obese may be vulnerable to biased attitudes from their patients, and their excess weight may negatively affect their credibility, level of trust and the inclination to follow their medical advice ${ }^{[31]}$. The truth of the matter is that physicians who are unwell physically or mentally may not practise effectively and safely because their patients may have a sixth sense of the doctor's wellness or unwellness. As Shanafelt says "....... if your doctors' talking to you about obesity and about cholesterol, about exercising, but it is very clear and evident this is missing in their own personal life, you wonder how important it really is" [32].

In a qualitative study in Nicolaus Copernicus University, Poland on "What kind of general practitioner do I need for smoking cessation?" patients' experiences of their physicians' behavior were predominantly negative, and resulted mainly from the physicians' passivity. An alarming demotivating activity, noted by some patients, was their physician's own smoking habits. Most participants admitted they would feel more motivated to stop smoking if their physician was a non-smoker. Some of the patients remarked, "When I was sitting in the surgery and the GP kept on explaining that I must do this and that, and a moment later he was saying - 'let's go, have a smoke', the motivation disappeared straightway" - "In my health centre, there is no GP who wouldn't smoke (...) And so if the GP himself smokes he will not advise [me] to quit for health reasons" ${ }^{[17]}$.

Frank et al, from Emory University, have shown that physicians' disclosure of healthy personal behaviors improves their credibility and ability to motivate. They are better promoters of a healthy lifestyle for their patients and their families ${ }^{[3]}$.

The Code of Ethics of The Canadian Medical Association makes it a fundamental responsibility of physicians to maintain and promote their own health and cultivate training and practice environments that provide physical and psychological safety and encourage health-seeking behaviors. This directive recognizes the importance of psychological well-being. In a survey aimed to evaluate the prevalence of burnout and satisfaction with worklife balance in US physians, it was found that more than $50 \%$ of them experienced professional burnout and were less likely to be satisfied with work-life balance [32]. The Israeli Society of Lifestyle Medicine (ISLM) joined with the Israeli Medical Association (IMA) to initiate a forum with other IMA leaders to better understand the extent of the problem by conducting a 
survey which yielded 4,800 responses. Unfortunately, the results were disturbing, with wide discrepancies in levels of stress, eating habits, smoking and exercise. Consequently, they have established various workgroups which are active and hopefully will prove rewarding ${ }^{[34]}$.

To adequately and ethically address the physical, psychosocial and spiritual concerns of patients, "Lifestyle Medicine Physicians" need to work under the guidance of experts in these domains. It is the responsibility of medical schools to organise well-planned and structured training programs to achieve these goals.

\section{CONCLUSION}

"Epidemiologic,ecologic,and interventional studies have repeatedly indicated that most chronic illnesses,including cardiovascular disease,cancer and type 2 diabetes, are the result of lifestyles fueled by poor nutrition and physical inactivity".

\section{Dr. Balazs Bodai [1]}

Lifestyle medicine is much more than dealing with individual patients.It is the skill set physicians who,with strong basic knowledge, would be able to identify the multiple factors tied to individual 's health, provide individualized advice and succefully change menance of chronic lifestyle-related diseases.

\section{Source of Funding}

This research did not receive any specific grant from funding agencies in the public, commercial, or not-for-profit sectors.

\section{Disclosure Statement}

The author has no conflicts of interest to disclose.

\section{Acknowledgements}

Dr. J P Miller (Gastroenterologist Manchester, United Kingdom) deserves special thanks for language editing and for his kind, motivating and stimulating discussions throughout the preparation of this paper.

The author is also indebted to Prof. Nicolino Ambrosino (Respirologist Italy) and Prof. Garry J Egger (Lifestyle Medicine Consultant Australia) for their scholarly advice to improve the manuscript.

\section{REFERENCES}

1. Bodai BI, Nakata TE, Wong WT et al. Lifestyle Medicine: A Brief Review of Its Dramatic Impact on Health and Survival. Perm J. 2018; 22:17-025. doi:10.7812/TPP/17-025

2. NCD Countdown 2030: Worldwide trends in non-communicable disease mortality and progress towards Sustainable Development Goal target 3.4.-Lancet. 2018 Sep 22;392(10152):1072-88.

3. Hyman MA, Ornish D, Roizen M. Lifestyle medicine: Treating the causes of diseases. Altern Ther Health Med. 2009; 15(6):12-4.

4. Rippe JM. Lifestyle Medicine: The Health Promoting Power of Daily Habits and Practices-Am J Lifesyle Med. 2018; 12(6):499512.

5. ACLM. American College of Lifestyle Medicine -Definition of Lifestyle Medicine---Available from http:// lifestylemedicine.org. [cited April 20, 2020]

6. Egger GJ, Binns AF, Rossner S. The emergence of "Lifestyle Medicine" as a structured approach for management of chronic diseases-Med J Australia. 2009;190(3):143-145.

7. Dysinger WS. Lifestyle Medicine Competencies for Primary Care Physicians- Am Med Assoc J Ethics. 2013; 15(4):306-310.
8. Boelen C. The Five Star Doctor: An Asset to Health Care Reform -WHO Geneva 1993.

9. Keto J, Jokelainen J, Timonen M, Linden K, Ylisaukkooja T. Physicians discuss the risks of smoking with their patients, but seldom offer practical cessation support- Substance Abuse Treatment, Prevention, and Policy, 2015; 10:43.

10. Center for Advancing Health. A New Definition of Patient Engagement: What Is Engagement and Why Is It Important? Washington, DC: Center for Advancing Health; 2010.

11. Shaw R, Sharon McKenzie S, Taylor T, Olafiranye O, BoutinFoster C, Ogedegbe G. Beliefs and Attitudes Toward Obstructive Sleep Apnea Evaluation and Treatment Among Blacks- J Natl Med Assoc. 2012; 104(11-12):510-19.

12. Yeh B-IL, Kong ID. The Advent of Lifestyle Medicine-- J Lifestyle Med 2013; 3(1):1-8.

13. Marriott BM (Editor). Not Enough Eating- Overcoming Underconsumption of Military Operational Rations. Institute of Medicine (US) Committee on Military Nutrition Research; National Academies Press (US) Washington (DC) 1995; 11.

14. Gardner G, Halweil B, Peterson JA. Underfed and overfed: the global epidemic of malnutrition. 2000 Washington (DC): World watch Inst.

15. Puska $\mathrm{P}$ et al. (Editors). The North Karelina Project-20-year results and experiences. Finland, Helsinki, National Public Health Institute, 1995.

16. Dowse GK, Gareeboo H, Alberti KG, Zimmet P, Tuomilehto J, Purran A, et al. Changes in population cholesterol concentrations and other cardiovascular risk factor levels after five years of the non-communicable intervention programme in Mauritius-BMJ 1995; 311:1255-59.

17. Buczkowski K, Marcinowicz L, Czachowski S, Piszczek E, Sowinska A. "What kind of general practitioner do I need for smoking cessation?" Results from a qualitative study in Poland. BMC Family Practice 2013; 14:159.

18. Puchalski C, Ferrell B, Virani R, Otis-Green S, Baird P, Bull J, Chochinov $\mathrm{H}$, et al. Improving the quality of spiritual care as a dimension of palliative care: the Report of the Consensus Conference-J Palliat Med. 2009; 12(10):885-904.

19. Puchalski CM, Vitillo R, Hull SK, Reller N. Improving the spiritual dimension of whole person care: reaching national and international consensus. J Palliat Med. 2014; 17(6):642-56.

20. Da Silva GPF, Nascimento FAB, Macedo TPM, Morano MT, Mesquita R, Pereira EDB. Religious coping and religiosity in patients with COPD following pulmonary rehabilitation- Int $\mathrm{J}$ COPD 2018; 13:175-181.

21. Maslach C, Jackson SE, Leiter MP. Maslach Burnout Inventory Manual. 3rd ed. Palo Alto, CA: Consulting Psychologists Press; 1996.

22. Williams E, Konrad TR, Linzer M, McMurray J, Pathman DE, Gerrity $M$, et al. Refining the measurement of physician job satisfaction: results from the physician worklife survey. Med Care. 1999;37(11):1140-54

23. Lloyd S, Streiner D, Shannon S. Burnout, depression, life and job satisfaction among Canadian emergency physicians. J Emerg Med. 1994; 12(4):559-65.

24. Doolittle BR, Windish DM, Seelig CB. Burnout, coping, and spirituality among internal medicine resident physicians. J Grad Med Educ. 2013; 5(2):257-61.

25. McCord G, Gilchrist VJ, Grossman SD, King BD, McCormick KE, Oprandi AM, Schrop SL, et al. Discussing spirituality with patients: a rational and ethical approach- Ann Fam Med. 2004; 2(4):35661.

26. Baumann SL, Englert R. A comparison of three views of spirituality in oncology nursing- Nurs Sci Q. 2003; 16(1):52-9.

27. Franzen AB. Influence of Physicians' Beliefs on Propensity to Include Religion/Spirituality in Patient Interactions. J Religion Health, 2018; 57(4):1581-97.

28. Ellis MR, Vinson DC, Ewigman B. Addressing spiritual concerns of patients: family physicians' attitudes and practices. J Fam Pract. 1999; 48(2):105-9.

29. Egger GJ, Binns AF, Rossner SR. The emergence of "lifestyle medicine" as a structured approach for management of chronic disease. Med J Aust 2009; 190:143-5.

30. Howe M, Leidel A, Krishnan SM, Weber A, Rubenfire M, Jackson EA. Patient-related diet and exercise counseling: do providers' own lifestyle habits matter? Prev Cardiol. 2010; 13(4):180-5. 
31. Puhl RM, King KM. Weight discrimination and bullying.-- Best Pract Res Clin Endocrinol Metab. 2013; 27(2):117-27.

32. Shanafelt TD, Hasan O, Dyrbye LN, Sinsky C, Satele D, Sloan J, West CP. Changes in Burnout and Satisfaction With Work-Life Balance in Physicians and the General US Working Population Between 2011 and 2014._Mayo Clin Proc. 2015; 90(12):1600-01

33. Frank E, Breyan J, Elon L. Physician disclosure of healthy personal behaviors improves credibility and ability to motivateArch Fam Med. 2000; 9(3):287-90.

34. Malatskey L, Hekselman I, Afek S. Lifestyle Medicine Around the World: Lifestyle Medicine in Israel_Am J Lifestyle Med -2019-https://doi.org/10.1177/1559827619880533 